\title{
Factors Influencing Postoperative Recovery and Time Off Work of Patients with Benign Indications for Surgery - Results of a Prospective Study
}

\author{
Einflussfaktoren auf die postoperative Genesung und \\ Krankschreibungsdauer bei Patientinnen mit benigner \\ Operationsindikation - Ergebnisse einer prospektiven Studie
}

\section{(C) (1) $\Theta$}

Authors

Sophie Strozyk ${ }^{1}$, Klaus-Dieter Wernecke ${ }^{2,3}$, Jalid Sehouli ${ }^{4}$, Matthias David ${ }^{4}$

\section{Affiliations}

1 Klinik für Chirurgie, Campus Charité Mitte, Charité Universitätsmedizin Berlin, Berlin, Germany

2 Charité - Universitätsmedizin Berlin, Berlin, Germany

3 Sostana GmbH, Berlin, Germany

4 Klinik für Gynäkologie mit Zentrum für onkologische Chirurgie, Campus Virchow-Klinikum, Charité Universitätsmedizin Berlin, Berlin, Germany

Key words

gynecological operation, quality of life, recovery

Schlüsselwörter

gynäkologische Operation, Lebensqualität, Rekonvaleszenz

received 28.1.2020

revised $\quad 7.4 .2020$

accepted 8.4.2020

\section{Bibliography}

DOI https://doi.org/10.1055/a-1157-8996

Geburtsh Frauenheilk 2020; 80: 723-732 @ Georg Thieme Verlag KG Stuttgart · New York | ISSN 0016-5751

\section{Correspondence}

Prof. Dr. med. Matthias David

Charité - Universitätsmedizin Berlin,

Campus Virchow-Klinikum, Klinik für Gynäkologie

Augustenburger Platz 1, 13353 Berlin, Germany

matthias.david@charite.de

Deutsche Version unter:

https://doi.org/10.1055/a-1157-8996

\section{ABSTRACT}

Objectives The study aimed to answer a number of questions: Which medical, psychological and sociodemographic factors affect the recovery of women after gynecological surgery for benign indications? Does patients' health-related quality of life improve after surgical intervention? How long are patients signed off work postoperatively? How do patients assess their own capacity to work?

Method Study population: All women between the ages of 18 and 67 years who underwent gynecological surgery for benign indications at the Charité Campus Virchow Clinic over a 7-month period were consecutively enrolled in the study. Four standardized patient surveys (the first survey [T0] was carried out in hospital, T1 at 1 week, T2 at 6 weeks and T3 at 78 months after discharge by telephone interview) were carried out using evaluated questionnaires to record patients' recovery (Recovery Index), quality of life (RAND-36), satisfaction, complications, sociodemographic information and time off work with a medical sick note. Relevant medical and demographic data were also collected. Statistical analysis was carried out using univariate statistical tests for descriptive analysis and complex multifactorial statistical procedures to record observations over time.

Results A total of 182 patients were included in this study (participation rate: 70\%). Relevant prior operations $(p=0.01)$, in-hospital $(p=0.004)$ and postoperative complications $(p<0.001)$, preoperative psychological wellbeing $(p=0.01)$, physical functioning $(p=0.005)$ and postoperative anxiety $(p=0,006)$ had a significant impact on recovery (Recovery Index) and changed significantly over time $(p<0.001)$. The invasiveness of the surgery or sociodemographic parameters (including migration background) had no significant effect. Health-related quality of life (measured with the RAND-36 questionnaire) also improved postoperatively. More invasive surgical interventions were associated with longer sick leave times and, to a certain extent, with a poorer evaluation of patients' capacity to work. 
Conclusion Recovery after gynecological surgery is a multifactorial process. This survey of a patient population identified psychological and physical factors which influence recovery but did not find significant sociodemographic parameters affecting recovery. Irrespective of these findings, gynecological surgery for benign indications resulted in an improvement in health-related quality of life. Prospective studies need to investigate whether psychological interventions could reduce preoperative fear and thereby improve postoperative recovery.

\section{ZUSAMMENFASSUNG}

Fragestellung Welche medizinischen, psychischen und soziodemografischen Faktoren beeinflussen die Rekonvaleszenz von Frauen nach einer gynäkologischen Operation mit benigner Indikation? Bessert sich die gesundheitsbezogene Lebensqualität der Patientinnen nach dem operativen Eingriff? Wie lange sind Patientinnen postoperativ arbeitsunfähig geschrieben; wie schätzen Patientinnen ihre Arbeitsfähigkeit selbst ein?

Methodik Studienkollektiv: Eingeschlossen wurden konsekutiv alle Frauen von 18 bis 67 Jahren in einem 7-monatigen Zeitraum, die aufgrund einer benignen Indikation am Campus Virchow-Klinikum der Charité gynäkologisch operiert wurden. Es wurden 4 standardisierte Patientinnenbefragungen (1. Befragung [T0] während des stationären Aufenthalts; T1 1 Woche, T2 6 Wochen und T3 7-8 Monate nach Entlassung als Telefoninterview) mittels evaluierter Fragebögen u.a. zur Erfassung von Genesung (Recovery Index), Lebensqualität (RAND-36), Zufriedenheit, aufgetretenen Komplikationen, soziodemografischen Angaben und Krankschreibungsdauer durchgeführt. Erfasst wurden außerdem relevante medizinische und demografische Daten. Die statistische Auswertung erfolgte deskriptiv mittels univariater statistischer Tests und mithilfe komplexer mehrfaktorieller statistischer Verfahren unter Erfassung des zeitlichen Verlaufs der Beobachtungen.

Ergebnisse Insgesamt konnten 182 Patientinnen in diese Studie einbezogen werden (Teilnahmequote: $70 \%$ ). Relevante Voroperationen $(p=0,01)$, peristationäre $(p=0,004)$ und postoperative Komplikationen $(p<0,001)$, präoperatives psychisches Wohlbefinden $(p=0,01)$ sowie physische Funktionsfähigkeit $(p=0,005)$ und postoperative Ängste $(p=0,006)$ hatten einen signifikanten Einfluss auf die Genesung (sog. Recovery Index), die sich insgesamt im zeitlichen Verlauf signifikant änderte $(p<0,001)$. Die Invasivität der durchgeführten Operation oder soziodemografische Parameter (inkl. Migrationshintergrund) hatten keinen signifikanten Einfluss. Auch die gesundheitsbezogene Lebensqualität (RAND-36) verbesserte sich postoperativ. Eine zunehmende Invasivität des operativen Eingriffs war mit einer längeren Krankschreibungsdauer und teilweise mit einer schlechteren Einschätzung der Arbeitsfähigkeit verbunden.

Schlussfolgerung Die Genesung nach einer gynäkologischen Operation ist ein multifaktorielles Geschehen. Im untersuchten Kollektiv konnten sowohl physische als auch psychische Einflussgrößen, nicht jedoch signifikante soziodemografische Parameter als Einflussfaktoren identifiziert werden. Unabhängig davon führt eine gynäkologische Operation bei benigner Indikation zu einer Verbesserung der gesundheitsbezogenen Lebensqualität. Prospektive Studien sollten z. B. prüfen, ob eine psychologische Intervention die präoperative Angst reduzieren und so die Rekonvaleszenz verbessern kann.

\section{Introduction}

Convalescence is viewed as a process or as a time of recovery after illness or surgery [1]. Postoperative recovery cannot simply be measured with individual parameters such as freedom from pain. Instead, it is a complex multidimensional process which includes social and economic elements in addition to physical and psychological aspects [2,3]. To date, there are very few prospective studies which have investigated the influence of several concomitant factors and their impact over time.

The time until patients can return to work after gynecological surgery for benign indications is often relatively long [4]. Obviously, the invasiveness and complexity of the gynecological surgery, the patient's expectations with regard to the duration of the recovery and the patient's preoperative, functional state of health all have a predictive value on the length of time until the patient can return to work; however, it appears that this time may also depend on the recommended sick leave period $[5,6]$. Recommendations by doctors about the appropriate length of time off work for patients who undergo hysterectomy or another type of gynecological surgery vary considerably. There are currently no evidence-based guidelines on the appropriate length of time to be off work $[7,8]$. The international data on benign dis- eases is inconsistent. According to a data analysis carried out in Great Britain, the recommended time off work after abdominal hysterectomy for benign indications ranges from 2 to more than 12 weeks [9]. Johansen et al. reported in 2008 that less than half of women who undergo hysterectomy returned to work again 1 week after the end of the recommended time off work [10]. Instead, the majority of patients extended their sick leave beyond the recommended time on their own initiative [10].

Postoperative complications do not just negatively affect health-related quality of life, they often also lead to an extended sick leave and are additionally associated with poorer physical condition and persistent or intense feelings of anxiety [11 - 13].

To date, very few investigations have looked at whether sociodemographic factors also have an impact on postoperative recovery after surgery. In their study, Brölmann et al. found no significant association between patients' level of education and the time until returning to work after gynecological surgery [4]. However, unemployment was found to be a risk factor for developing depression in patients who had recently undergone hysterectomy [14]. Similarly, low social support by the patient's partner, family or friends was associated with a poorer outcome [15]. There are currently no larger systematic studies on postoperative recovery times after gynecological surgery in Germany. 
The aim of this prospective single-center study was therefore to find out whether and how medical, psychological and/or sociodemographic factors affect postoperative recovery.

\section{Method and Patient Population}

\section{Study design}

All patients who underwent surgery for benign gynecological disease in the Gynecological Department of the Charité Campus Virchow University Clinic in Berlin (Director: Prof. Dr. Dr. h.c. J. Sehouli) over a 7-month period from June to December 2015 were consecutively invited to participate in the study. Patients were interviewed at 4 different times postoperatively: the first interview took place when patients were still in hospital (T0: face-to-face interview); 3 subsequent interviews were carried out as telephone interviews at 1 week (T1), 6 weeks (T2) and 7-8 months (T3) after being discharged from hospital. All interviews (T0 bis T3) were carried out by the same study author (S.S.). When carrying out interviews with Turkish-speaking patients, S.S. was assisted by a trained student assistant with a Turkish migration background. Patients were interviewed at the earliest on the first postoperative day and at the latest on the day they were discharged from hospital. Before patients were interviewed, they were provided with material informing them about the research project and data protection. The questionnaire and the leaflets were available in German and Turkish.

\section{Inclusion criteria}

Patients aged between 18 and 67 years who underwent surgery during the above-mentioned period, gave their written consent to the study, and agreed to allow their phone number to be recorded for the subsequent interviews $\mathrm{T} 1$ to $\mathrm{T} 3$ were included in the study.

\section{Questionnaires and planned course of the study}

The first questionnaire which was used for the in-hospital interview consisted of 4 parts (A-D). Part A collected sociodemographic data such as housing situation, job or occupation, and school-leaving qualifications (for analysis, patients were grouped into patients with a low level of education = no educational qualifications or only attended primary school or a few years of secondary school; patients with a moderate level of education = General Certificate of Secondary Education, or completed secondary modern or middle school; patients with high level of education = school-leaving examinations qualifying for admission to university or vocational baccalaureate or university diploma/ polytechnic degree). Information on the patient's satisfaction with her current living situation, income, professional and family situation, health, and general satisfaction with her life were also recorded; a Likert scale between 0 ("entirely dissatisfied") and 10 ("entirely satisfied") was used to assess satisfaction. Part B of the questionnaire covered information on migration and acculturation (Frankfurt Acculturation Scale [FRAKK]) [16]. Our study used the 2006 definition of "migration background" of Schenk et al.: a person has a migration background if the person does not report German is their first language or if the person was not born in Ger- many or has at least one parent to whom this applies [17]. Part C consisted of an evaluated questionnaire on health (RAND-36). Part $\mathrm{D}$ asked the patient about how she assessed her current capacity to work and about any feelings of anxiety $[18,19]$.

In addition to the information obtained from the questionnaires, patients' medical data from their patient files were also used for data analysis.

In the 3 post-hospital telephone surveys T1 to T3, patients were always asked about postoperative complications such as wound infections or secondary bleeding, whether they currently required painkillers, whether they were currently able to work and how strong their feeling of anxiety was $(0=$ "no anxiety" to 10 = "highest level of anxiety" on an 11-point Likert scale; for the evaluation, "anxiety" was grouped into "very little anxiety" =0 3 points, "moderate anxiety" $=4-6$ points, "strong anxiety" $=7-$ 10 points). Patients evaluated their current capacity to work on a scale ranging from $0=$ "incapable of work" to 10 = "fully able to work". If the patient was not employed or otherwise in work, she was asked how well she was able to carry out her daily responsibilities (for example, household tasks). In addition, patients were asked the 10 questions of the Recovery Index questionnaire [19]. During the second telephone interview (T2), patients were additionally asked how long they were on sick leave or when they would be able to fully return to work. The first day of sick leave was defined as the first day after being discharged from hospital.

At the last post-hospital survey (T3) at 7-8 months after discharge from hospital, patients were additionally asked again about their state of health using the RAND-36 questionnaire.

\section{Statistical analysis of the questionnaires}

The completed questionnaires were pseudonymized using a numerical sequence and analyzed using SPSS (IBM SPSS Statistics Version 24).

\section{Evaluation of the Recovery Index (RI)}

Data analysis was based on the approach of Kluivers et al. [19]. A high RI score stood for a high level of recovery [19]. The Recovery Index was originally developed as a tool to survey patients who had undergone hysterectomy [19] and was then used by Vonk Noordegraaf et al. to evaluate other patients who underwent abdominal gynecological surgery [20]. As our study also included patients who underwent breast surgery, the original text ("Even without doing any activity, I still regularly experience abdominal pain") was amended into a more general statement “... feel pain in the operated area".

\section{Evaluation of the RAND-36}

The RAND-36 questionnaire of the RAND Corporation was used to record patients' health-related quality-of-life. This questionnaire corresponds to the questions of the Short Form 36 Health Survey questionnaire (SF-36) [18]. It consists of 36 questions which cover eight different domains: energy/exhaustion, physical functioning, pain, perception of general health, physical role functioning, emotional role functioning, social functioning, and psychological wellbeing. It also includes a question about changes in health status over time [18]. The questions in the RAND-36 used at timepoint T0 all refer to the time immediately prior to the surgical procedure 
and were then partially amended for use in the subsequent surveys, for example, question 21: "How strong was your pain in the 4 weeks before the operation?". The questionnaire was amended again for the interview at timepoint T3, with the second question of the RAND-36 questionnaire amended as follows: "Compared to the period before the operation how would you describe your current state of health?". The RAND-36 questionnaire was also used to investigate whether preoperative physical functioning or preoperative psychological wellbeing had an impact on postoperative recovery. For this evaluation, the scores for individual questions focusing on the domains "physical functioning" and "psychological wellbeing" from the first interview (T0) were added up.

\section{Classification according to level of invasiveness}

As a first step, two of the authors (S. S., M.D.) classified the surgical interventions into 4 levels of invasiveness similar to the classification used by Vonk Noordegraaf et al. in their 2014 study:
1. "not very invasive"
2. "slightly invasive"
3. "moderately invasive"
4. "very invasive" [20].

As the case numbers in Group 1 were very low, they were grouped together with the cases in Group 2 ("slightly invasive"), resulting in just 3 levels of invasiveness ( $\triangleright$ Table 1 ). Some patients underwent combined procedures, with the individual procedures categorized into different levels of invasiveness. In such cases, patients were classed according to the most invasive procedure.

The level of significance was set at $p=0.05$. Internal consistency to measure the reliability of the questionnaires used in the study was determined using Cronbach's alpha coefficient ( $\alpha$ ), with SPSS used to calculate Cronbach's alpha coefficient. A Cronbach's alpha coefficient of more than 0.80 indicates a good internal consistency and therefore a reliable testing method [21].

\section{Statistical methods used for evaluation}

The investigated factors which could potentially have an impact included both nominally and ordinally scaled variables as well as metric scaled measurements. Independent variables were considered target values for the mean Recovery Index score, making them dependent metrically scaled variables. All evaluated variables were combined into a general linear mixed model to evaluate their impact on the course of the dependent variable (i.e., the Recovery Index score) over time. A stepwise backward elimination of the independent variables was carried out, in which the respective variable with the highest $p$-value (highest redundancy) was excluded from the analysis. The value of goodness-of-fit of the model was measured using the Akaike information criterion (AIC). Based on this principle, independent variables are excluded from analysis until the point when the goodness-of-fit of model, measured using the AIC, no longer improves.

Two of the research questions were examined with the help of univariate non-parametric tests, as the underlying data did not meet the requirements for parametric tests. Wilcoxon signedrank test was used to compare the RAND-36 scores obtained at timepoint T0 with those from timepoint T3. Mann-Whitney U-test was used to evaluate capacity to work when comparing 2 inde-
- Table 1 Classification of surgical interventions into 3 levels of invasiveness (modified from Vonk Noordegraaf et al. [2014] [20]).

Class 1 - slightly invasive:

- Laser vaporization of condylomata on the vulva/vagina/ectocervix

- Curettage for miscarriage

- Hysteroscopy (with myoma/polyp ablation, if indicated)

- Curettage

- Loop conization

- Removal of vaginal vault granulations

- Abscess incision and drainage with placement of tamponade for breast/vulvar abscess

- Marsupialization for Bartholin's cysts

- Skinning vulvectomy

- Suturing of vaginal margins to treat erosion in the vicinity of TVT sling

- Excision of necrotic tissue and breast scar correction

Class 2 - moderately invasive:

- Laparoscopy (myoma enucleation, resection of ovarian/paratubal/ hydatid cysts, salpingotomy, adenectomy, ovarian wedge resection, [partial] salpingectomy, resection of the uterosacral ligament, hysterosacropexy, incision of pseudo-peritoneal cysts, coagulation of perforation site following uterus perforation during curettage)

- Laparoscopically assisted vaginal hysterectomy (LAVH) with/without adnexal surgery

- Laparoscopically assisted supracervical hysterectomy (LASH)

- Total laparoscopic hysterectomy (TLH) with adnexal surgery

- Vaginal hysterectomy without adnexal surgery

- Anterior and posterior colporrhaphy

- Removal of breast implant and capsule with wound revision

- Implant replacement and breast scar revision

Class 3 - very invasive:

- (Mini-) laparotomy (myoma enucleation, hysterectomy with/without adnexal surgery, supracervical hysterectomy, adenectomy, ovariectomy, resection of ovarian cysts, salpingotomy, omentectomy, resection of peritoneal retention cysts, excision of parts of the uterine wall to treat adenomyosis of the uterus, removal of necrotic tissue and suturing of the uterine wall to treat wall dehiscence, adhesiolysis, chromopertubation)

- Subcutaneous mastectomy with reconstruction

- Mastopexy

- Breast reconstruction with latissimus dorsi flap

- Breast implant placement

pendent groups, and Kruskal-Wallis $\mathrm{H}$ test was used to compare 3 groups. If the latter test showed a significant result, a Bonferroni test was carried out as a post-hoc test for pairwise comparisons of characteristics of the independent variables.

\section{Ethics vote and data protection}

This research project was advised and approved by the Ethics Committee of Charité Berlin, Ethikausschuss I, Campus Charité Mitte (application number EA1/111/15). The study complies with the guidelines of Charité on ensuring good scientific practice and with the Berlin Law on Data Protection. 


\section{Results}

\section{Study population}

During the observation period from June to December 2015, a total of 269 patients were asked to participate in the study during their stay in hospital. 81 patients (30\%) declined to participate. 57 of these patients (again $70 \%$ ) had a migration background; inadequate command of German meant that 34 of these 57 women were unable or unwilling to participate in the study. Other reasons cited for declining to participate included, in particular, the 3 planned subsequent telephone surveys. Some of the women felt that the questionnaire was too big or that some of the questions were too personal. Others felt that participating in the study was too overwhelming for psychological reasons (e.g., because of their depressed mood postoperatively). Six of the 188 patients who participated had to be subsequently excluded from in the study because the resected specimen was found to be malignant. Ultimately, questionnaires from 182 women were included at timepoint T0. At this timepoint (T0), the surveyed women were between 19 and 67 years old (mean 40.45; SD: 11.56). A total of 49 patients $(27 \%)$ had a migration background.

\section{Response rate for every timepoint of the survey}

Out of the original 182 patients, 151 patients (38\%) could be reached at timepoint T1, 128 patients $(70 \%)$ could be contacted at timepoint T2, and 106 patients (58\%) were reached at timepoint T3 for the respective telephone survey. The Recovery Index (RI) questionnaire showed a good rate of reliability for all survey timepoints (T1- $\alpha$ : 0.870; T2- $\alpha$ : 0.813; T3- $\alpha$ : 0.813). This was also the case for the RAND-36 ( $\vee$ Table 5).

\section{Invasiveness of surgical intervention}

A high Recovery Index (RI) score indicates a good recovery. As the level of invasiveness of the procedure increased, the RI was only found to clearly decrease at timepoint T1. Overall, the RI score increased over time ( $\triangleright$ Fig. 1) irrespective of the level of invasiveness of the surgical procedure.

\section{Peri- and postoperative complications}

Five patients (3\%) had complications from surgery during their stay in hospital. The patients who experienced complications during their stay in hospital reported significantly lower RI scores. Similarly, RI scores were also lower if complications occurred postoperatively in the time after discharge from hospital up until the third survey at timepoint T3.

\section{Preoperative psychological wellbeing}

The applicable domain of the RAND-36 was used to evaluate preoperative psychological wellbeing. The mean score of the study population for this domain was 65.98 (SD: 18.13) at timepoint T0.

\section{Preoperative physical functioning}

Out of a maximum possible score of 100 , the mean score for this domain at timepoint T0 was 85.16 (SD: 18.90) for all study participants.

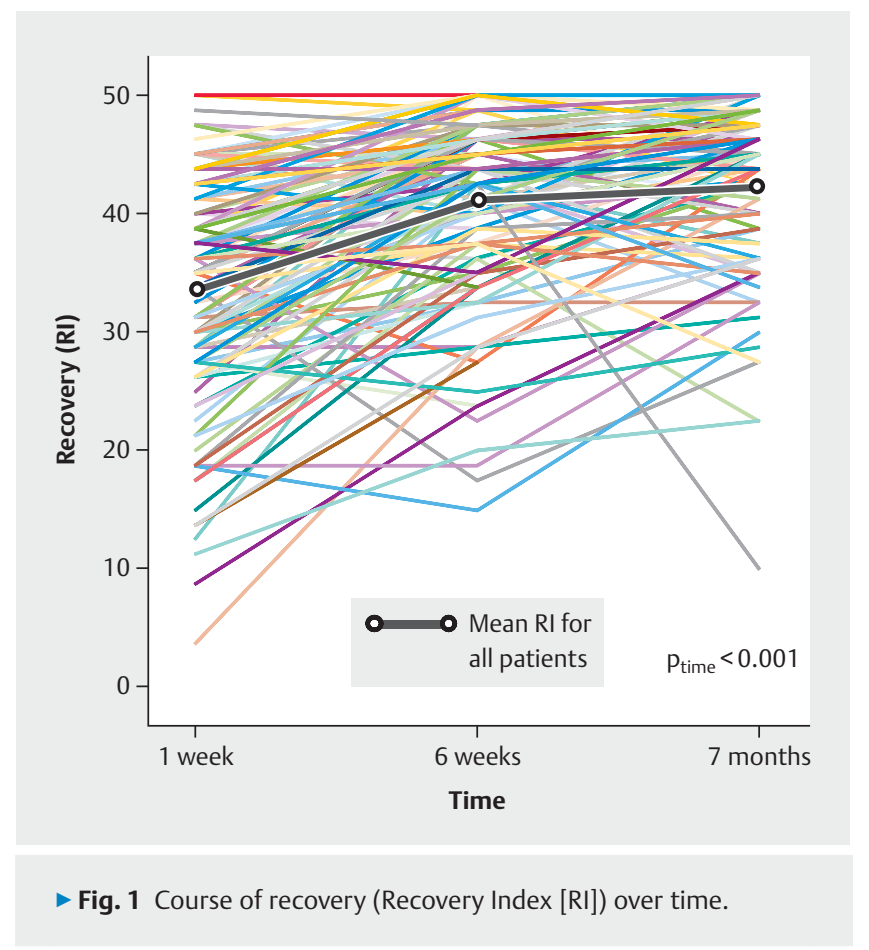

\section{Life satisfaction}

During their stay in hospital, patients were asked about their level of satisfaction ( 0 to a maximum of 10 points on a Likert scale) with regard to different aspects of their life. The mean satisfaction score for all surveyed aspects of their life was 7.37 (SD: 1.38).

\section{Postoperative feelings of anxiety}

The mean score at timepoint T1 was 2.59 (SD: 2.64). 49 patients (33\%) stated that they had no feelings of anxiety, and only 4 patients (3\%) reported a score of 9 points. At timepoint T2 the mean score was 2.57 (SD: 2.54). 37 patients (29\%) reported not feeling anxious at all, while 2 women (2\%) responded with a very high score, reporting 9 and 10 points, respectively. The mean score at timepoint T3 was 2.88 (SD: 2.40). 25 patients (24\%) had no feelings of anxiety and 1 patient (1\%) reported the highest level of anxiety. The overall RI score decreases when patients report increasing levels of anxiety.

The general linear mixed model, which included all previously described independent variables scored at the different time points, confirmed that RI scores increased significantly over time postoperatively ( $\triangleright$ Fig. 1 ).

- Table 2 shows the results of this model, i.e. prior to backward elimination. To improve the accuracy of the model, the following influencing factors were successively eliminated from the full model: household, committed relationship, formal education, occupation, migration background, satisfaction with life situation, level of invasiveness of the surgical procedure, pre-existing conditions, and patient age. $>$ Table 3 shows the results of the final model, i.e. the variables which had a significant impact on the course of the RI after backward elimination of independent variables. Sociodemographic variables such as migration background or level of education had no significant impact. Evaluation of med- 
- Table 2 Results of the evaluation based on a general linear mixed model prior to backward elimination, using the Recovery Index (RI) as the target value.

\begin{tabular}{|l|r|r|}
\hline Influencing factors & P-value & F-value \\
\hline Level of invasiveness & 0.034 & 3.476 \\
\hline In-hospital complications & 0.021 & 5.452 \\
\hline Pre-existing medical condition(s) & 0.134 & 2.277 \\
\hline Previous operations & 0.029 & 4.892 \\
\hline Living alone & 0.231 & 1.448 \\
\hline School qualifications & 0.715 & 0.337 \\
\hline In work & 0.670 & 0.182 \\
\hline In a committed relationship & 0.661 & 0.193 \\
\hline Migration background & 0.152 & 1.907 \\
\hline Feelings of anxiety & 0.026 & 3.700 \\
\hline Postoperative complications & $<0.001$ & 77.773 \\
\hline Patient age & 0.491 & 0.478 \\
\hline Satisfaction with life situation & 0.194 & 1.709 \\
\hline Preoperative physical functioning & 0.096 & 2.815 \\
\hline Preoperative psychological wellbeing & 0.189 & 1.747 \\
\hline Time (improvement of Rl over time) & $<0.001$ & 82.559 \\
\hline
\end{tabular}

ical factors potentially affecting recovery showed that in-hospital and postoperative complications, relevant previous operations, and preoperative physical functioning had a significant impact on the recovery process (RI). Of the evaluated psychological factors, postoperative feelings of anxiety and preoperative psychological wellbeing had a significant impact on the course of the RI, but sociodemographic factors did not. Moreover, overall recovery (RI) improved over time ( $\vee$ Fig. 1).

\section{Health-related quality of life}

The data were evaluated to see whether the scores of individual domains changed over time. All scores, with the exception of the domains "emotional role functioning" and "perception of general health", improved significantly from timepoint T0 to timepoint T3 $(\triangleright$ Tables 4 and 5 ).

\section{Duration of time signed off work}

Six weeks after discharge from hospital, patients who were employed or in training were asked about the length of time they were signed off work and patients who were self-employed or freelancers were asked how long it had been until they were fully able to work again. These questions applied to 132 patients. The remaining women in the study were either not working or had already retired at the time of the survey. Of these 132 women, 95 patients (i.e., $72 \%$ ) were surveyed again and the length of time they were off work was recorded. All medical sick notes were issued by registered physicians. The mean time off work was 24.08 days (SD: 15.32). - Fig. 2 shows the time signed of work as a function of the level of invasiveness of the procedure. As ex-

- Table 3 Additional statistics based on the general linear mixed model after backward elimination, using the Recovery Index (RI) as the target value.

\begin{tabular}{|c|c|c|c|}
\hline Influencing factors & Coefficient & $95 \%$ confidence interval & p-value \\
\hline \multicolumn{4}{|l|}{ Complications occurred in hospital } \\
\hline - yes & -7.935 & $-13.226--2.644$ & 0.004 \\
\hline - no & Reference & Reference & Reference \\
\hline \multicolumn{4}{|l|}{ Previous operation(s) } \\
\hline - yes & -2.138 & $-3.751--0.526$ & 0.010 \\
\hline \multicolumn{4}{|l|}{ Feelings of anxiety } \\
\hline - a little & 3.209 & $1.258-5.159$ & 0.001 \\
\hline - moderate & 2.531 & $0.615-4.448$ & 0.010 \\
\hline - strong & Reference & Reference & Reference \\
\hline \multicolumn{4}{|l|}{ Postoperative complications } \\
\hline - yes & -5.928 & $-7.214--4.642$ & $<0.001$ \\
\hline - no & Reference & Reference & Reference \\
\hline \multicolumn{4}{|l|}{ Timepoint } \\
\hline - $\mathrm{T} 1$ & -6.662 & $-7.863--5.462$ & $<0.001$ \\
\hline . $\mathrm{T} 2$ & -1.224 & $-2.223--0.225$ & 0.017 \\
\hline . T3 & Reference & Reference & Reference \\
\hline Preoperative physical functioning & 0.0635 & $0.0195-0.108$ & 0.005 \\
\hline Preoperative psychological wellbeing & 0.0587 & $0.0141-0.1033$ & 0.010 \\
\hline Constant term & 33.875 & $29.005-38.745$ & $<0.001$ \\
\hline
\end{tabular}


- Table 4 Descriptive statistics for individual RAND-36 domains at timepoints T0 and T3 ( $\mathrm{N}=$ number, SD = standard deviation, $\alpha=$ Cronbach's alpha).

\begin{tabular}{|c|c|c|c|c|c|}
\hline RAND-36 domain & $\mathbf{N}$ & Mean & Median & SD & $\alpha$ \\
\hline \multicolumn{6}{|l|}{ Physical functioning } \\
\hline - T0 & 182 & 85.16 & 90.00 & 18.90 & 0.880 \\
\hline$\cdot \mathrm{T} 3$ & 106 & 90.24 & 100.00 & 15.86 & 0.876 \\
\hline \multicolumn{6}{|c|}{ Physical role functioning } \\
\hline - T0 & 182 & 58.24 & 75.00 & 43.51 & 0.903 \\
\hline . T3 & 106 & 83.49 & 100.00 & 32.35 & 0.896 \\
\hline \multicolumn{6}{|c|}{ Emotional role functioning } \\
\hline - T0 & 182 & 69.05 & 100.00 & 39.96 & 0.839 \\
\hline . T3 & 106 & 72.96 & 100.00 & 39.07 & 0.858 \\
\hline \multicolumn{6}{|l|}{ Energy/exhaustion } \\
\hline - T0 & 182 & 49.86 & 50.00 & 19.38 & 0.805 \\
\hline$\cdot \mathrm{T} 3$ & 106 & 54.62 & 55.00 & 17.74 & 0.825 \\
\hline \multicolumn{6}{|c|}{ Psychological wellbeing } \\
\hline - T0 & 182 & 65.98 & 66.00 & 18.13 & 0.814 \\
\hline$\cdot \mathrm{T} 3$ & 106 & 70.72 & 74.00 & 17.76 & 0.852 \\
\hline \multicolumn{6}{|l|}{ Social functioning } \\
\hline - T0 & 182 & 82.14 & 100.00 & 26.26 & 0.874 \\
\hline . T3 & 106 & 92.10 & 100.00 & 17.28 & 0.794 \\
\hline \multicolumn{6}{|l|}{ Pain } \\
\hline - T0 & 182 & 65.38 & 67.50 & 33.50 & 0.878 \\
\hline$\cdot \mathrm{T} 3$ & 106 & 90.47 & 100.00 & 20.67 & 0.906 \\
\hline \multicolumn{6}{|c|}{ Perception of general state of health } \\
\hline - T0 & 182 & 65.11 & 70.00 & 21.33 & 0.767 \\
\hline$\cdot \mathrm{T3}$ & 106 & 66.27 & 72.50 & 24.17 & 0.854 \\
\hline \multicolumn{6}{|c|}{ Changes to state of health } \\
\hline - T0 & 182 & 42.31 & 50.00 & 24.42 & - \\
\hline. $\mathrm{T} 3$ & 106 & 66.04 & 50.00 & 27.64 & \\
\hline
\end{tabular}

- Table 5 Comparison between the individual domains of the RAND-36 survey for timepoints T0 and T3 - results of significance testing.

\begin{tabular}{|l|r|}
\hline RAND-36 domain & p-value \\
\hline Physical functioning & 0.001 \\
\hline Physical role functioning & $<0.001$ \\
\hline Emotional role functioning & 0.129 \\
\hline Energy/exhaustion & 0.026 \\
\hline Psychological wellbeing & 0.008 \\
\hline Social functioning & 0.001 \\
\hline Pain & $<0.001$ \\
\hline Perception of general state of health & 0.326 \\
\hline Changes to state of health & $<0.001$ \\
\hline
\end{tabular}

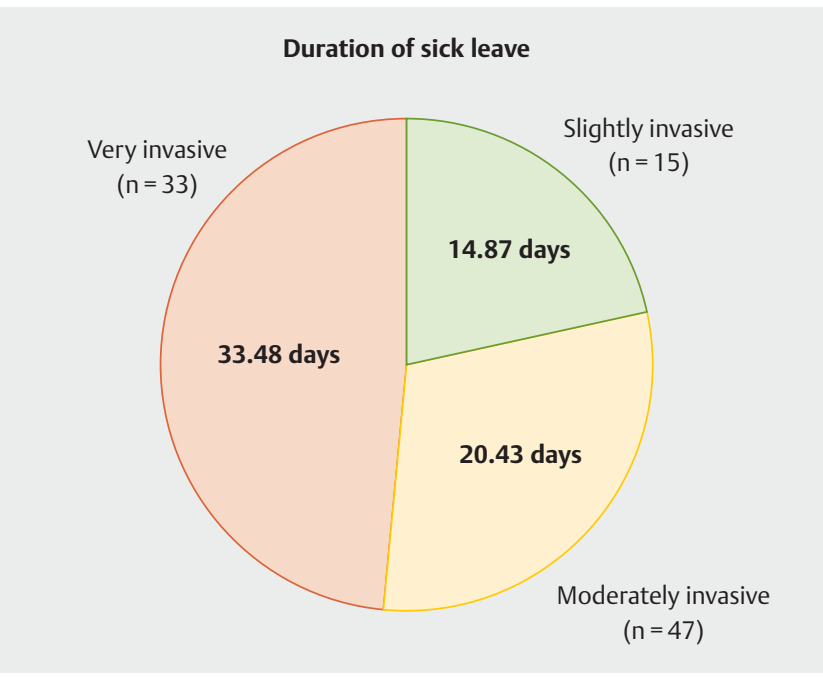

Fig. 2 Time signed off work in days, according to the 3 levels of invasiveness ( $\mathrm{n}$ ). 
pected, the higher the level of invasiveness, the longer the time off work.

\section{Estimation of fitness for work}

As described above, patients were asked at each subsequent telephone interview how they evaluated their current fitness for work using a scale ranging from $0=$ "incapable of work" to $10=$ "fully able to work". At timepoint T1 the mean patient score was 5.22 (SD: 3.11), at timepoint T2 it was 7.87 (SD: 2.46), and at timepoint T3 it was 8.52 (SD: 2.10). Patients' fitness for work increased continually over time.

Scores were subsequently compared to see whether postoperative fitness for work changed according to the level of invasiveness of the procedure and whether the occurrence of postoperative complications had an impact on patients' estimation of their fitness for work. At timepoint T1, the estimation of patients' fitness for work differed significantly between strongly and moderately invasive procedures and between strongly and slightly invasive procedures $(p<0.001$ and $p=0.002$, respectively). At timepoint $\mathrm{T} 2$ only the difference between very and moderately invasive was significant $(p=0.028)$. At time T3 there was no significant difference in the estimation of fitness for work relating to the invasiveness of the procedure.

Analysis showed, however, that the occurrence of postoperative complications led to a significantly poorer estimation of fitness for work at all 3 timepoints (T1: $p<0.001, T 2$ : $p<0.001, T 3$ : $\mathrm{p}=0.018)$.

\section{Discussion}

Prospective studies on the factors influencing postoperative recovery which are based on complex statistical analysis and investigate changes over time are rare. Most previous studies which looked at recovery after gynecological procedures in the widest sense of the term compared the effects of different hysterectomy techniques. In one study published in 2008, Persson et al. compared recovery times for laparascopic and abdominal hysterectomies, and in a second study from 2010 they compared recovery times after supracervical and total abdominal hysterectomy and found no differences in postoperative recovery [12,22]. In contrast, according to the data by Brummer et al., laparoscopic hysterectomy had the shortest stay in hospital and the shortest time off work compared to vaginal or abdominal procedures [23]. The study by Vonk Noordegraaf et al. on which we partly based the idea for our study compares different gynecological abdominal procedures and divided them into 4 different classes according to their level of invasiveness [20]. Vonk Noordegraaf et al. found that increasingly levels of invasiveness of surgical procedures were associated with an increased risk of longer times off work [20]. Another study has shown that the time until patients can resume everyday activities becomes longer when the invasiveness of the procedure increases [24]. Similarly, the patients in our study who underwent the most invasive procedures were off work longest.

Our results about the recovery process were unexpected. Contrary to prior assumptions, more invasive procedures were not associated with delayed recovery. Other factors such as prior operations or pre-existing medical conditions played a greater role in the recovery process and led to a significantly poorer course of recovery. According to a study by Dessources and colleagues, patients with specific pre-existing medical conditions or whose preexisting medical conditions meant that they had a higher ASA classification were more likely to require readmission to hospital after the initial discharge [25]. According to a study by Theunissen et al., ASA classification is also a predictor of postoperative recovery: patients with ASA classification level III had a poorer recovery than patients with ASA class I [26].

Postoperative complications are associated with longer times off work, a higher rate of readmissions to hospital, and a higher risk of developing chronic postoperative pain $[13,22,25,26]$. Moreover, postoperative complications can result in a reduced capacity to work and higher feelings of anxiety [11]. Our study found that strong feelings of anxiety postoperatively had a negative impact on recovery. According to a study by Kagan et al., feelings of anxiety which are already present preoperatively have a negative impact on postoperative recovery [27]. According to other studies, this can lead to higher levels of postoperative pain or even result in chronic postoperative pain $[28,29]$. Our study did not investigate what the impact of complications which occurred in prior surgical procedures was on recovery. This point will be examined in further planned study.

An earlier study by Reitsma et al. showed an improvement in quality of life postoperatively after gynecological surgery [30]. The studies published to date have primarily focused on women who underwent hysterectomy. The studies mainly reported improvements in physical wellbeing, but often also found a positive impact on patients' psychological situation and social relations [31 -33]. Only one study reported that hysterectomy had no relevant impact on the patients' psychological state [34].

The patients surveyed in our study who were in work were signed off work for a mean of 24.1 days (the time off work after slightly invasive procedures was 15 days; the time off work after moderately invasive procedures was 20 days, and the mean time signed off work after very invasive procedures was 34 days). The time off work after slightly invasive procedures appears to be relatively long. However, similar figures have been reported elsewhere, for example in the study by Brummer et al. which compared the effects of different hysterectomy procedures [23]. Women who had an abdominal hysterectomy were off work for 32 days, women who had a vaginal hysterectomy were off work for 30 days, and women who underwent laparoscopic hysterectomy were off work for 22 days after surgery [23]. In the 2014 study by Vonk Noordegraaf et al., the time until returning to work was even longer, with 60 days off work following moderately invasive and 69 days off work after very invasive surgical procedures; the time off work after slightly invasive procedures was 14 days [20]. Brölmann et al. reported in their study that 8 weeks after a gynecological operation, only $50 \%$ of patients had fully returned to work, $30 \%$ of patients were working part of the time by this point, and $20 \%$ were still signed off work [4].

However, it should be noted that it is not possible, based on the number of days on which women are signed off work with a medical sick note, to differentiate between patient-related (not robust enough yet, etc.) and physician-related factors (unclear basis for determining duration of sick leave, subjective influences 
culminating in an extension of sick leave to accommodate patient wishes, and similar). Moller et al. noted that gynecologists who issued sick notes for women undergoing hysterectomy gave longer periods of sick leave to women whose work involved heavy physical work compared to women who only had to carry out light physical work [8]. There are some general indications that patients who are self-employed and therefore unable to earn any income in the time they are off work tend to return to work earlier than employees, although not all studies have borne this out [5, $20,35]$. Sometimes sick leave is extended beyond the recommended period at the request of the affected women [10]. In their study, Bouwsma et al. found that both the period until patients returned to work and the period until various physical activities were resumed were longer than the period recommended by experts [24]. Moreover, patient expectations of having a long period of sick leave can lead to an extended sick leave [20]. These factors could have resulted in patients in our study being on sick leave for a relatively long time after not very invasive procedures, even though the expected physical limitations and pain after such operations are usually low(er). Because of the resulting time away from work, this also has an economic relevance for society as a whole.

One week after being discharged from hospital, women without postoperative complications had recovered around $60 \%$ of their capacity to work and after six weeks they had recovered $80 \%$ of their capacity to work. After 7-8 months, patients had recovered a mean of $90 \%$ of their capacity to work. Women who experienced postoperative complications reported a significantly lower capacity to work at all 3 timepoints (T1: 30\%, T2: 60\%, T3: $70 \%)$. These figures are comparable with the findings in the study of Doll et al. [11].

\section{Strengths and Limitations of the Study}

\section{Strengths}

To our knowledge, this is the first study on this topic in Germany which measures changes over time using 4 timepoints spaced at relatively long intervals, uses internationally validated questionnaires and expressly includes women with a migration background.

\section{Limitations}

1. It was not possible to question all of the patients over the entire period of the study. At timepoint T3 only $58 \%$ of the women originally enrolled in the study were still available for questioning.

2. Postoperative recovery is a complex, multidimensional process. It is possible that our questionnaire did not cover all aspects.

3. The study was a single-center study.

\section{Conclusions for Clinical Practice}

The development and implementation of so-called Fast Track Surgery (FTS) or Enhanced Recovery After Surgery (ERAS) programs to reduce time in hospital, complication rates, the rates of re- admission to hospital, and hospital costs are now quite common [36-38]. Such programs mainly focus on the immediate postoperative phase when patients are still in hospital.

Vonk Noordegraaf et al. have developed an e-health program for the Netherlands specifically for gynecological patients [39, 40]. In this program, women who underwent gynecological surgery for benign indications were given personalized recommendations with regard to resuming everyday activities and returning to work. The aim was to make it easier to reintegrate at work [39, 40]. Such programs along with the necessary scientific monitoring and evaluation should be developed and implemented in Germany to particularly support those patients who are at risk of having longer postoperative recovery times. With the help of further studies based on our results, it should be possible to identify patients who are at risk. In addition, such programs could help reduce the time off work, particularly after less invasive procedures which our study found to be associated with relatively long sick leave times, by offering targeted information and support.

\section{Note}

This study was supported by a research grant from the German Society for Psychosomatic Gynecology and Obstetrics (DGPFG).

\section{Conflict of Interest}

The authors declare that they have no conflict of interest.

\section{References}

[1] Berlin-Brandenburgische Akademie der Wissenschaften. „Rekonvaleszenz", bereitgestellt durch das Digitale Wörterbuch der deutschen Sprache. Online: www.dwds.de/wb/Rekonvaleszenz; Stand 24.07.2019

[2] Allvin R, Berg K, Idvall E et al. Postoperative recovery: a concept analysis. J Adv Nurs 2007; 57: 552-558. doi:10.1111/j.1365-2648.2006.04156.x

[3] Lee L, Tran T, Mayo NE et al. What does it really mean to "recover" from an operation? Surgery 2014; 155: 211-216. doi:10.1016/j.surg.2013. 10.002

[4] Brolmann HA, Vonk Noordegraaf A, Bruinvels DJ et al. Can prolonged sick leave after gynecologic surgery be predicted? An observational study in The Netherlands. Surg Endosc 2009; 23: 2237-2241. doi:10.1007/s00464-008-0287-0

[5] Clayton M, Verow P. A retrospective study of return to work following surgery. Occup Med (Lond) 2007; 57: 525-531. doi:10.1093/occmed/ kqm082

[6] Evenson M, Payne D, Nygaard I. Recovery at home after major gynecologic surgery: how do our patients fare? Obstet Gynecol 2012; 119: 780-784. doi:10.1097/AOG.0b013e31824bb15e

[7] Naidu M, Sultan AH, Thakar R. Convalescence advice following gynaecological surgery. J Obstet Gynaecol 2012; 32: 556-559. doi:10.3109/ 01443615.2012 .693983

[8] Moller C, Ottesen M, Kehlet $\mathrm{H}$ et al. [Convalescence recommendations after hysterectomy. A study of opinions among Danish physicians]. Ugeskr Laeger 2001; 163: 7043-7047

[9] Clayton M, Verow P. Advice given to patients about return to work and driving following surgery. Occup Med (Lond) 2007; 57: 488-491. doi:10.1093/occmed/kqm063

[10] Johansen P, Al-Khafagi SK, Thostesen LM et al. [Analysis of need for sick leave after hysterectomy]. Ugeskr Laeger 2008; 170: 1465-1468 
[11] Doll KM, Barber EL, Bensen JT et al. The impact of surgical complications on health-related quality of life in women undergoing gynecologic and gynecologic oncology procedures: a prospective longitudinal cohort study. Am J Obstet Gynecol 2016; 215: 457.e1-457.e13. doi:10.1016/j. ajog.2016.04.025

[12] Persson P, Brynhildsen J, Kjolhede P. Short-term recovery after subtotal and total abdominal hysterectomy-a randomised clinical trial. BJOG 2010; 117: 469-478. doi:10.1111/j.1471-0528.2009.02468.x

[13] Wodlin NB, Nilsson L, Kjolhede P. Health-related quality of life and postoperative recovery in fast-track hysterectomy. Acta Obstet Gynecol Scand 2011; 90: 362-368. doi:10.1111/j.1600-0412.2010.01058.x

[14] Wang XQ, Lambert CE, Lambert VA. Anxiety, depression and coping strategies in post-hysterectomy Chinese women prior to discharge. Int Nurs Rev 2007; 54: 271-279. doi:10.1111/j.1466-7657.2007.00562.x

[15] Webb C, Wilson-Barnett J. Self-concept, social support and hysterectomy. Int J Nurs Stud 1983; 20: 97-107

[16] Bongard S, Kelava A, Aazami GD et al. Entwicklung der Frankfurter Akkulturationsskala (FRAKK) - Unveröffentlichtes Manuskript. Frankfurt: Johann Wolfgang Goethe-Universität, Institut für Psychologie; 2007: 25

[17] Schenk L, Bau AM, Borde T et al. [A basic set of indicators for mapping migrant status. Recommendations for epidemiological practice]. Bundesgesundheitsbl 2006; 49: 853-860. doi:10.1007/s00103-006-0018-4

[18] Hays RD, Sherbourne CD, Mazel RM. The RAND 36-Item Health Survey 1.0. Health Econ 1993; 2: 217-227

[19] Kluivers KB, Hendriks JC, Mol BW et al. Clinimetric properties of 3 instruments measuring postoperative recovery in a gynecologic surgical population. Surgery 2008; 144: 12-21. doi:10.1016/j.surg.2008.03.027

[20] Vonk Noordegraaf A, Anema JR, Louwerse MD et al. Prediction of time to return to work after gynaecological surgery: a prospective cohort study in the Netherlands. BJOG 2014; 121: 487-497. doi:10.1111/14710528.12494

[21] Wirtz MA, Hrsg. Dorsch - Lexikon der Psychologie. 19. Aufl. Göttingen: Hogrefe; 2019

[22] Persson P, Kjolhede P. Factors associated with postoperative recovery after laparoscopic and abdominal hysterectomy. Eur J Obstet Gynecol Reprod Biol 2008; 140: 108-113. doi:10.1016/j.ejogrb.2008.03.006

[23] Brummer TH, Jalkanen J, Fraser J et al. FINHYST 2006-national prospective 1-year survey of 5,279 hysterectomies. Hum Reprod 2009; 24 : 2515-2522. doi:10.1093/humrep/dep229

[24] Bouwsma EVA, Anema JR, Vonk Noordegraaf A et al. Using patient data to optimize an expert-based guideline on convalescence recommendations after gynecological surgery: a prospective cohort study. BMC Surg 2017; 17: 129. doi:10.1186/s12893-017-0317-8

[25] Dessources K, Hou JY, Tergas Al et al. Factors associated with 30-day hospital readmission after hysterectomy. Obstet Gynecol 2015; 125 : 461-470. doi:10.1097/aog.0000000000000623

[26] Theunissen M, Peters ML, Schepers ] et al. Recovery 3 and 12 months after hysterectomy: epidemiology and predictors of chronic pain, physical functioning, and global surgical recovery. Medicine 2016; 95: e3980. doi:10.1097/md.0000000000003980
[27] Kagan I, Bar-Tal Y. The effect of preoperative uncertainty and anxiety on short-term recovery after elective arthroplasty. J Clin Nurs 2008; 17 : 576-583. doi:10.1111/j.1365-2702.2007.01968.x

[28] Theunissen M, Peters ML, Bruce J et al. Preoperative anxiety and catastrophizing: a systematic review and meta-analysis of the association with chronic postsurgical pain. Clin J Pain 2012; 28: 819-841. doi:10.1097/AJP.0b013e31824549d6

[29] Pinto PR, Mclntyre T, Nogueira-Silva C et al. Risk factors for persistent postsurgical pain in women undergoing hysterectomy due to benign causes: a prospective predictive study. J Pain 2012; 13: 1045-1057. doi:10.1016/j.jpain.2012.07.014

[30] Reitsma ML, Vandenkerkhof EG, Johnston SL et al. Does health-related quality of life improve in women following gynaecological surgery? J Obstet Gynaecol Can 2011; 33: 1241-1247

[31] Einarsson JI, Suzuki Y, Vellinga TT et al. Prospective evaluation of quality of life in total versus supracervical laparoscopic hysterectomy. J Minim Invasive Gynecol 2011; 18: 617-621. doi:10.1016/j.jmig.2011.06.003

[32] Lee CF, Wen FH, Lin SS et al. Changing quality of life in hysterectomized women. J Formos Med Assoc 2009; 108: 414-422. doi:10.1016/s09296646(09)60086-3

[33] Thakar R, Ayers S, Georgakapolou A et al. Hysterectomy improves quality of life and decreases psychiatric symptoms: a prospective and randomised comparison of total versus subtotal hysterectomy. BJOG 2004; 111: 1115-1120. doi:10.1111/j.1471-0528.2004.00242.x

[34] Yang YL, Chao YM, Chen YC et al. Changes and factors influencing health-related quality of life after hysterectomy in premenopausal women with benign gynecologic conditions. J Formos Med Assoc 2006; 105 : 731-742. doi:10.1016/s0929-6646(09)60201-1

[35] Hussey L, Turner S, Thorley $\mathrm{K}$ et al. Work-related sickness absence as reported by UK general practitioners. Occup Med (Lond) 2012; 62: 105111. doi:10.1093/occmed/kqr205

[36] Kehlet H, Wilmore DW. Evidence-based surgical care and the evolution of fast-track surgery. Ann Surg 2008; 248: 189-198. doi:10.1097/SLA. 0b013e31817f2c1a

[37] Glaser G, Dowdy SC, Peedicayil A. Enhanced recovery after surgery in gynecologic oncology. Int J Gynaecol Obstet 2018; 143 (Suppl. 2): 143146. doi:10.1002/ijgo.12622

[38] Muallem MZ, Dimitrova D, Pietzner K et al. Implementation of Enhanced Recovery After Surgery (ERAS) Pathways in Gynecologic Oncology. A NOGGO-AGO* survey of 144 Gynecological Departments in Germany. Anticancer Res 2016; 36: 4227-4232

[39] Vonk Noordegraaf A, Anema JR, van Mechelen W et al. A personalised eHealth programme reduces the duration until return to work after gynaecological surgery: results of a multicentre randomised trial. BJOG 2014; 121: 1127-1135; discussion 1136. doi:10.1111/1471-0528. 12661

[40] Vonk Noordegraaf A, Huirne JA, Pittens CA et al. eHealth program to empower patients in returning to normal activities and work after gynecological surgery: intervention mapping as a useful method for development. J Med Internet Res 2012; 14: e124. doi:10.2196/jmir.1915 